\title{
IN THE FOOTSTEPS OF JULIUS KÖNIG'S PARADOX
}

Abstract. König's paradox, that he presented for the first time in 1905, preserved the same structure in all his papers: there was a number that at the same time was and was not finitely definable. Still, he changed the way for forming it, and both its consequences and its solutions changed as well. In the present paper we are going to follow the story of König's paradox, that is an intriguing mix of labelling, solving, critizing an "object" from different viewpoints and for different aims.

Zusammenfassung. Königs Paradoxon, das er zuerst im Jahr 1905 vorstellte, blieb in Hinblick auf seine Struktur in allen seinen Werken gleich: es handelt sich um eine Zahl, die gleichzeitig endlich definierbar und nicht endlich definierbar ist. Dennoch änderte er im Laufe der Zeit die Bildungsweise des Paradoxons, seine Konsequenzen und seine Auflösungen. Die vorliegende Arbeit folgt der Geschichte von Königs Paradoxon als einer faszinierenden Mischung von Etikettierungen, Auflösungen und Kritiken eines "Objektes" aus verschiedenen Blickwinkeln und mit unterschiedlichen Zielsetzungen.

Keywords: $20^{\text {th }}$ century logic - paradoxes - set theory - infinite

AMS codes: 01A55, 03A05

\section{Introduction}

Julius König presented what is known as his 'paradox' in 1905: there is a number that at the same time is and is not finitely definable. It was used by him as a step for (trying to) prove that the continuum was not well-ordered, and only later he shifted the focus to the contradiction itself and tried to find solutions. We are going to follow his efforts in our paper.

\section{Biographical notes.}

Julius (Gyula) König was born in Györ on $16^{\text {th }}$ December $1849 .{ }^{1}$ He enrolled at the Medical Department of the University of Vienna and at the same time attended lectures on mathematics. After a short stay in Vienna, he went to Heidelberg, where he could devote himself both to natural sciences and to medicine. He got his doctoral degree in 1870 with a thesis on the theory of modular

\footnotetext{
1 See [Szénássy 1992, 217-223, 233-255, 332-335] that contains also a complete bibliography of König.
} 
functions, although his first essay treated a medical subject (Beiträge zur Theorie der elektrischen Nervenreizungen). It seems that the arrival at Heidelberg of Leo Königsberger had been very influential on König's decision of choosing a mathematical subject for his doctoral work. ${ }^{2}$ Then König spent half a year in Berlin, where he attended lectures of Weierstrass and Kronecker. He was appointed professor of the Pedagógusképzö Kara (Teacher Training College) of Budapest in 1873 and Professor of the Third Department of the Technical University one year later. He was the Dean of the Faculty of engineering and also Rector of the University. During his life Julius König contributed to many areas of mathematics: algebra, analysis, geometry, number theory, set theory. His teaching activity extended outside the university as he held the view that the professors of the universities should always be in touch with secondary education, by guiding and helping work there. Hence, he established the programme of education in the field of commerce in Hungary and worked out the algebra part of the 1879 programme for secondary schools. He was one of the founders of the Bolyai János Matematikai Társulat (János Bolyai Mathematical Society) in Hungary and became a member of the Magyar Tudományos Akadémia (Hungarian Academy of Science) in 1889. In 1905 König retired (at the age of 56!), and this allowed him to spend the last part of his life working on his own approach to set theory, logic and arithmetic. He continued to give lectures at the university about these topics. A monograph about them was published in 1914, the year after his (sudden) death.

\section{The framework of König's paradox}

König's paradox was born and grew up inside set theory. Three things should be stressed.

a) In the first years of the $20^{\text {th }}$ century no antinomy ${ }^{3}$ about set theory had yet been discovered (See [Moore - Garciadiego 1981]). Around $1895,{ }^{4}$ Cantor had noticed a strange effect that could come out of his set theory: the totality of all ordinal numbers could be well-ordered

\footnotetext{
2 See http://www-history.mcs.st-andrews.ac.uk/Biographies/Konig_Julius.html.

3 I recall here the Moore-Garciadiego distinction between a contradiction and an antinomy/ a paradox: the latter is a contradiction that attracts the focus on itself, while the former is a means inside a proof by reductio ad absurdum. In the present paper I will then use indifferently the words 'antinomy' and 'paradox' in this sense.

4 According to Bernstein [1905, 187], Cantor had noticed the "contradiction" related to the existence of a maximum ordinal as early as 1895, and would have informed Hilbert in 1896. As Cantini [2009, 879] recalls, we have also the evidence of 1) a letter to Hilbert of 26.09.1897, where he sketches the argument that the totality of alephs cannot be at the same time well-defined and conceivable as a completed set; 2) a letter to Dedekind of 28.07.1899, where Cantor, on the basis of the theorem that ordinal numbers are linearly ordered, stated that the multiplicity of ordinal numbers is itself well ordered, but stressed that the it is not a set - hence no ordinal can be assigned to it and no contradiction can come out.
} 
and, hence, if it were a set, an ordinal number could be assigned to it. Such an ordinal number would belong to the set (as the set is the totality of ordinal numbers) and would not belong to the set (according to a well-known theorem about well-ordered sets) at the same time. This means that the totality of ordinal numbers is an inconsistent multiplicity. According to Cantor, this gave us a precious piece of information about set theory: the totality of all ordinals cannot be a set. (Later, when a list of antinomies became fixed in the literature, this fact came to be read in the following terms: Cantor noticed the "antinomy of the maximum ordinal" and tried to solve it through the distinction between consistent and inconsistent multiplicities. However, this was not his way of thinking at the time he noticed this issue).

b) In the years around the end of the $19^{\text {th }}$ century and the beginning of the $20^{\text {th }}$, the focus of the mathematicians interested in set theory were the continuum hypothesis (that was a certainty for Cantor) and the (connected) question of the trichotomy of the real numbers (about the continuum hypothesis see [Moore 1989]). Burali-Forti expressed the contradiction that later bore his name - and that was the first one concerning set theory to be published - in the paper "Una questione sui numeri transfiniti" [Burali-Forti 1897] as a means to prove that the trichotomy of the real numbers was untenable: if it held, it would produce a number $\Omega$ such that $\Omega+1>\Omega$ and $\Omega+1 \leq \Omega$. In his paper he gave the definition of well-ordered set and of perfectly ordered set. He believed that his description of well ordered sets was the same as that of Cantor and that a well ordered set was also a perfectly ordered set. On the contrary, Cantor's definition was wider than that Burali-Forti had attributed to him (in fact, he had forgotten Cantor's third condition). He admitted as much in a note that attached to his 1897 paper. He also affirmed that a perfectly ordered set was well ordered but not vice-versa ${ }^{5}$. He did not restate his proof but left it to the reader to determine which steps of his proof could be maintained. When this contradiction is mentioned in the literature, it is frequently

\footnotetext{
5 A wrong idea, as Poincaré noted, but he attributed it either to Couturat's translation or to the fault of the printer [Poincaré 1906, 304]. About the Burali-Forti paradox see also Copi [1958].
} 
inserted in a list of problems within set theory, i.e. in a list of antinomies that must be solved if we want to save set theory. Still, at the very beginning, in the mind of its author it was not a thing that undermined set theory: it was a means to understand an aspect of set theory that had still to be fully realized [Garciadiego 1992, 20-32]. Poincaré [1905], who was negative about set theory (with its reference to transfinite numbers), stressed that Burali-Forti's result contradicted Cantor's statement of the validity of the trichotomy, and therefore he considered Burali-Forti contradiction as an antinomy.

c) Russell, due to his philosophical (Kantian) education, was an antinomy-detector/collector. In 1896, by reviewing Arthur Hannequin's book Essai critique sur l'hypothèse des atomes dans la science contemporaine [Hannequin 1985], he wrote that collecting mathematical fallacies was worthwhile (See [Moore - Garciadiego 1981, 324]). He adopted Hannequin's opinion that set theory was contradictory, but he recognized [Russell 1896, 412] his alleged contradiction as the (usual) second Kantian antinomy: every composite substance both is and is not, made up of simple parts. In 1900 Russell had in mind an "antinomy of the infinite number" but he had no enough formal tools to formulate it (See [Moore Garciadiego 1981, 325]. On this topic see also [Coffa 1979], [Grattan-Guinness 1976, 1978, 1981] and [Moore 1988, 1995]). Peano's talk at the Paris international congress of philosophy convinced him about the acceptability of a logicist viewpoint. This led him to a deeper study of such an approach and in 1902 he built his famous antinomy [Russell 1902] which was not directed at Cantor's set theory but rather at Fregean logicism (without any aim of criticizing it). In his The Principles of Mathematics [Russell 1903] we find three contradictions mentioned: his own $(\S 100)$, that by Burali-Forti $(\S 310)$ and the Cantorian one (§344). We can say that they were antinomies, according to him, because they represented a problem in themselves (the focus was entirely on them), one that he tried to solve.

\section{König's 1904 talk}

At the Third International Mathematical Congress of 1904 in Heidelberg Julius König presented a proof of the fact that the continuum cannot be well-ordered (and consequently that the continuum hypothesis is false). 
Firstly, König proved the following6:

$\sum_{i=0}^{\infty} \overline{\overline{M_{i}}} \leq \prod_{i=0}^{\infty} \overline{\overline{M_{i}}} \leq\left(\sum_{i=0}^{\infty} \overline{\overline{M_{i}}}\right)^{\aleph_{0}}$

by tacitly using what would be later called "the axiom of choice".

Then he proved that, for a growing sequence of cardinals, the first inequality was a strict one ${ }^{7}$.

Therefore, the consequence was:

$\sum_{i=0}^{\infty} \overline{\overline{M_{i}}}<\left(\sum_{i=0}^{\infty} \overline{\overline{M_{i}}}\right)^{\aleph_{0}}$

At this step, he began his reduction ad absurdum: if the continuum could be well-ordered and its cardinality were an $\aleph_{\beta}$, from $\overline{\overline{M_{i}}}=\aleph_{\beta+i}$ we could obtain

$\aleph_{\beta+\omega}<\aleph_{\beta+\omega}^{\aleph_{0}}$

since $\sum_{i=0}^{\infty} \aleph_{\beta+i}=\aleph_{\beta+\omega}$.

The contradiction is clear if the formula

$\aleph_{\alpha}^{\aleph_{0}}=\aleph_{\alpha} \cdot 2^{\aleph_{0}}$

that had been proved in Bernstein's Inaugural Dissertation Untersuchungen aus der Mengenlehre [1901, 49] is applied to every ordinals. Namely, it follows that:

$\aleph_{\beta+\omega}^{\aleph_{0}}=\aleph_{\beta+\omega} \aleph_{\beta}=\aleph_{\beta+\omega}$.

The proof was not sound: it relied on an equivalence result $\left(\aleph_{\alpha} \aleph_{0}=\aleph_{\alpha} \cdot 2 \aleph_{0}\right)$ that Felix Bernstein had proved in his recent dissertation for finite ordinals and which König8 ${ }^{8}$ wongly considered valid for any ordinal $\alpha$. When the proceedings were published, in 1905, König presented his result under a conditional form: "if Bernstein's theorem were to hold in general, then the continuum could not be well-ordered".

Who was the first to discover the mistake is not clear. Certainly there was a deep discussion around this topic, after the Congress, at Wengen, in the Bernese Overland, where Cantor was spending his

\footnotetext{
${ }^{6}$ We recall here that the symbol $\overline{\bar{M}}$ represented the cardinality of the set $M$.

${ }^{7}$ Purkert [2015, 18-19] notes that this theorem was soon recognized as one of the fundamental results in set theory. It would be generalized in 1907 by the Russian Iwan Shegalkin, who called it "The theorem of König" (see [Shegalkin 1907, 332]) and by Zermelo [1908], independently. After Hausdorff's researches of 1906-1908, Lindenbaum and Tarski $[1926,310]$ eventually came to understand how König's theorem yields the stronger result that $2 \aleph_{0 \neq \aleph_{\beta}}$ for any limit ordinal $\beta$ cofinal with $\omega$ (see also G.H. Moore $[1982,88]$ ). Lolli $[2013,119]$ stresses that this part of the proof survived and offered the only provable result of ZF about the cardinality of the continuum.

8 Bernstein himself [1905b, 464] stated that his formula "von mir versehentlich in einem zu weiten Umfang ausgesprochen worden" ("it has been uttered by me accidentally in a too wide scope").
} 
holidays: Hilbert, Kurt Hensel, Hausdorff and Schoenflies took part in it [Schoenflies 1922, 100]. Kowalewski [1950, 202] has given origin to the legend that already the day after König's communication it turned out that König's proof was unsound: Zermelo had made such a discovery. This legend has been often reported (see, for example, [Meschkowski 1967, 165-166], [Moore 1982, 87], [Purkert/Ilgauds 1987, 161], [Oberschelp 1994, 11]). [Ferreirós 1999, 312] has doubted that it may well be that Kowalewski misremembered. Purkert [2015, 13-14] stresses that Kowalewski did not witness first hand, because his name did not appear in the official list of participants who attended the congress [Krazer 1950, 11-12].

Due to [Ebbinghaus 2007, 431] we have the transcript of Zermelo's postcard to Max Dehn (dated 24.10.1904) stating that: "König can be happy that the library in Heidelberg had closed so early; otherwise he might have made a fool of himself. Thus I had to wait for checking until my return to Göttingen. Then it was instantly obvious".

It seems that Zermelo had doubted the validity of Bernstein's formula already at Heidelberg, that he left Heidelberg on the same day of König's lecture (or on the early following day), that the university library there had already closed when König finished his lecture, and Zermelo could check Bernstein's dissertation only in Göttingen. We do not know whether he revealed his "suspicion" to anybody.

Guillemot [1981], Grattan-Guinness [2000, 334] and Purkert [2002, 9-12] affirmed that it was Felix Hausdorff who discovered the gap after the congress. Purkert [2015, 13-14] recalls that we have a letter from Felix Hausdorff to Hilbert (dated 29.09.1904 and quoted in [Hausdorff 2012, 330]) where he affirms that, after his return from Wengen, he had checked Bernstein's dissertation and found out that König's mistake was exactly where he expected. From this letter it is clear that: 1) the problem had not been concluded in Heidelberg, 2) it had been discussed also later in Wengen, 3) Hausdorff had the right idea in Wengen and got the possibility to check it only later in Göttingen. This confirms Schoenflies' first hand testimony [Schoenflies 1922, 100-101]: “To Hausdorff we owe thanks for undertaking careful examination of the range of validity of Bernstein's aleph relation”. Neither Schoenflies nor Hausdorff quote Zermelo, therefore, we can suppose that, even if Zermelo doubted of Bernstein's proof already in Heidelberg, he did not say that to anybody before he could be sure of it. The discussion about König's proof went on in Wengen (where Zermelo was 
not present), and there Hausdorff had the same doubt as Zermelo, but independently of him. When he was sure of his viewpoint, Zermelo also communicated it to König (as reported in the above quoted letter to Dehn), but König did not answer to him. Zermelo (in the above quoted letter to Dehn), after reporting his checking Bernstein's dissertation in Göttingen, adds: "In the meantime, however, König had found that out for himself while writing up his proof', therefore, it is clear that König's revision was independent of Zermelo's suggestions. We have a letter from König to Hilbert (dated 07.09.1904 - see Hilbert Papers 184/3 at the SUB Göttingen), where, after coming back from the days spent together, he communicated to him that the proof he had given in Heidelberg was not valid because Bernstein's theorem did not hold for the cases that were necessary in the proof. Maybe König checked Bernstein's theorem after Hausdorff's suggestion, maybe he had doubted of Bernstein's formula by himself. In a letter from Hilbert to Klein (dated 19.09.1904 [Frei 1985, 131]) Hilbert affirms: "Das interessanteste aber ist, dass sich der Bernsteinsche Satz, auf den sich König in seiner Aufsehn erregenden Vortrage stützte, als falsch herausgestellt hat. König hat dies selbst eingesehen und seinen Beweis zurückgezogen“" (The most interesting thing ist hat Bernestein's theorem, on which König relied in his sensational talk, has turned up to be false. König recognised this himself and withdrew his proof".) Hilbert does not mention Hausdorff.

In any case, König corrected his proof independently of Zermelo, and both Zermelo and Hausdorff had found out the mistake, independently from each other. At the end, König corrected his proof in the Proceedings.

Zermelo wrote also a letter to Hilbert (dated 24.09.1904) in which he offered a proof for the well ordering theorem. The proof was published in [Zermelo 1904] and mentioned by J. Hadamard [1905] that, when his note appeared (March 1905), was still waiting for the written official report of König's proof.

\section{König's 1905 second paper}

What is commonly known as König's paradox has an inner core, namely the existence of a number that at the same time is and is not "finitely definable". 9 This core appeared for the first time in 1905 ,

\footnotetext{
${ }^{9}$ For a survey of the role of the notion of definability in the first three decades of 20th century, see Lolli [2001].
} 
in the paper "Über die Grundlagen der Mengenlehre und das Potenz des Kontinuums" [König 1905b]. What is now known as König's paradox was at the very beginning the "absurdity" that would have followed the admissibility of the well-ordering of the continuum.

Before beginning his procedure, König recalled the Cantorian representation of the continuum as the set of the denumerably infinite sequences of integers $\left(a_{0}, a_{1}, \ldots\right)$, obtained by considering the interval $[0,1]$ (which is provably equivalent to the totality of the continuum), where the real numbers can be written as infinite continued fractions $\frac{1}{a_{1}+\frac{1}{a_{2}+\ldots \ldots}},-a_{0}, a_{1}, \ldots$ being integers (the representation consists of making a list of them). He also justified this representation by means of two axioms: one that affirms that such sequences (and their totality) are non-contradictory concepts, and the other that assures that such sequences are grounded in our consciousness because there are processes of our consciousness that satisfy the laws of formal logic and that stand in a oneto-one relation to the generation of the sequences of $a_{k}$. This is the case, no matter how such a relation comes to be. König was to formulate his opinion on this matter in a more precise and refined way later, in his 1914 book, but the core of his thought was already present: he was convinced that the basis of certainty in mathematics was its reflecting states of consciousness.

Furthermore, he stated that the continuum, being a set of well-ordered sets, defines an unbroken sequence of ordinals (the order-types of its elements) such that an ordinal is finitely definable if and only if the corresponding element of the continuum is finitely definable. He specified that an element of the continuum is said to be finitely defined if, "by means of a language capable of giving a definite form to our scientific thinking, we can in a finite span of time specify a procedure (law) that conceptually distinguishes that element of the continuum from any other one" [1905b, 146], and he immediately added that "it must expressly be emphasized that the finite conceptual differentiation demanded here is not to be confused with the demand for a well-defined, or even finite, procedure by which the $a_{k}$ can be determined". The conceptual differentiation is completely given by means of letters and punctuation marks, of which only a definite, finite number is available.

After these premises, his strategy was to stress the following:

1) the number of elements of the continuum that is finitely definable is denumerable, therefore there must be some elements that are not finitely definable; 
2) the elements of the continuum that cannot be finitely definable form a subset of the continuum itself. This subset, if the continuum is well-ordered, according to the definition of well-ordering, has a first element;

3) the subset built in 2) corresponds to a sequence of ordinals that should be not finitely definable by definition (as corresponding to elements of the continuum that are not finitely definable). Hence, its first element should be not finitely definable;

4) the first element can be described (with respect to the preceding ones, that are finitely definable) as "the first ordinal exceeding all of these in magnitude". The words in quotation marks are a finite definition of the ordinal: therefore, it is at the same time finitely definable and not finitely definable.

Immediately after this proof, König admitted that the same procedure could be applied, word for word, to every well-ordered nondenumerable set, in particular to the second number class $\mathrm{Z}\left(\aleph_{0}\right)$ defined as the totality of all order types of well-ordered sets of cardinality $\aleph_{0},{ }^{10}$ that Cantor had proved to be well-ordered. The result, in this case, would be that the set could not exist at all (since it would and would not be well-ordered at the same time). Still, König noticed, such a class is consistently defined without any doubt, and, hence, it must exist. König tried both to solve this problem and to preserve the first result (the continuum cannot be well ordered), by introducing a distinction between "set" and class". A set is "the totality of well-distinguished objects" (it is a "completed set"); a "class" is "a set in the process of becoming". ${ }^{11}$

The continuum should be considered a set because it is possible to individuate, and hence to distinguish from each other, its elements. They are the sequences $\left(a_{1}, a_{2}, \ldots, a_{k}, \ldots\right)$, where $a_{1}, a_{2}, \ldots$ are to be replaced by definite positive integers. On the contrary, the second number class $\mathrm{Z}\left(\aleph_{0}\right)$ is defined by the general property "of being order types of well-ordered sets of cardinality $\aleph_{0}$ ", and

\footnotetext{
10 Cantor's definition was [1932, 195-197]: "We define therefore the second number class as the collection of all [Inbegriff aller] numbers $\alpha$ (increasing in definite succession) which can be formed by means of the two principles of generation [add one unit and take for an order-type $\omega$ the next higher element, the limit-element][...] which are subject to the condition that all numbers preceding $\alpha$ (from 1 on) constitute a set of power equivalent to the first number class." (Engl transl. in [Dauben 1979, 98]).

11 We recall here that Cantor, after realizing the contradictions produced by the largest ordinal and by the largest cardinal, had distinguished between inconsistent multiplicities (like the set of all cardinal numbers) and consistent multiplicities. Later (1908) Zermelo would distinguish between sets (that he would introduce axiomatically) and a starting domain of objects which contains sets but that is not itself a set. John von Neumann in 1923 would propose a differentiation between sets and classes that allowed him to avoid the problems linked to sets that are too big. "Sets are the sets that are 'not too big', and classes are all totalities irrespective of their 'size'." [1923, 403] According to von Neumann's terminology, a class is a function; it can also be an argument if and only if it is a set, i.e. too big sets are functions but cannot be arguments. Hence, von Neumann uses the same labels 'sets' and 'classes' as König but attaching to them his specific meaning.
} 
this is not a rule for generating and individuating them. Therefore, they are not distinguishable, no method is given to individuate the elements of such a class, hence their totality cannot be considered a set. The procedure used above in the presented proofs holds only in the case of sets, but not in the case of classes; consequently, it cannot be applied to the second number class and no antinomy can be generated.

König stressed in a footnote at the end of the paper that his difference between classes and sets solved the problem of those paradoxes of the theory of ordinal numbers which Burali-Forti drew to the attention of the mathematicians [1905b, 149].

It is worthwhile to recall that König specified that "there exist elements of the continuum that we cannot 'think through to the end' and that they are nevertheless consistent; thus they are 'ideal' elements, if I may be permitted to use this expression in what is, to be sure, an entirely new sense" [1905b, 147]. The notion of "ideal" was already present in mathematics; in particular, the most recent use of the notion at that time had been done by Kummer [1847a and b, 1851] and Dedekind ([1871, 1877, 1895, 1968]; see Edwards [1980, 1983, 1992], Stillwell [2002, 439-461], Avigad [2006], Kleiner [2007, 50-54] ). The novelty to which König explicitly alluded was the criterion for its acceptability: its consistency. This criterion was derived from Hilbert, who had not yet linked it to the label "ideal" at that time, although he had contributed to the popularization of Dedekind's concept in his 1897 "Zahlbericht” (that König had introduced in Hungary [Szamuely 2006, 1] and had used ideal elements in his geometrical works [see Stillwell 2014]. He had only spoken of consistency as the condition for the (mathematical) existence of a concept (See for instance [Hilbert 1900, 1104-1105]). He began to introduce in 1923 the analogy between adding transfinite axioms to the finitary axioms of a theory and adding imaginary elements to the real numbers in the theory of complex numbers or adding ideal figures to real figures in geometry. Then, in his conference "Über das Unendliche" [Hilbert 1926] he spoke of the method of ideal elements and he fully expressed the connection that he saw between the introduction of ideal elements in a theory and their non-contradicting it: the latter was a condition necessary for allowing the former. "We come upon a [...] fundamental interpretation of the notion of infinity when we consider the method of ideal elements. [...] The ideal elements 'at infinity' have the advantage of making the system of the laws of connection as simple and perspicuous as is possible. [...] there is a 
condition, a single but absolutely necessary one, to which the use of the method of ideal elements is subject, and that is the proof of consistency“" [1926, 379-383]. Hilbert added a Kantian reference to his thought about the infinite: the infinite is nowhere; it is only an "idea" in Kantian sense, a concept of reason that transcends all experience and through which the concrete is completed so as to form a totality. On this topic see [Peckhaus 1990], Majer [1993a and 1993b], Franchella [1998, 29 and 50-57], Murawski [2002], Tapp [2013, 156-165],

\section{Reactions}

In Britain, Ernest William Hobson was the first to state that set theory had to be revised due to the existence of its paradoxes (produced by the set of all cardinals/ordinals). Namely, in his paper "On the General Theory of Transfinite Numbers and Order Types" [Hobson 1905], he considered the Burali-Forti contradiction as an antinomy that put doubts on set theory [Garciadiego 1992, 143144]. With respect to König's paper, he considered its content in a correct way: not as containing an antinomy but as containing a proof of a theorem by reductio ad absurdum. Although he was convinced that the continuum could not be well-ordered, Hobson criticized König's 1905 proof because he did not consider valid the distinction between numbers that are and numbers that are not finitely definable [Hobson 190712]. Namely, if it is regarded as essential to a finite definition that it should be expressible by means of a finite numbers of words and symbols, each of which has a definite and unique meaning, then no irrational number is capable of such definition. Actually, the simplest possible definition of any of the ordinary irrational number, such as $e, \pi, \ldots$ involves the introduction of a number $n$ (see, for instance the definition of $e$ as $\sum_{i=0}^{\infty} \frac{1}{n !}$ ) which has no unique meaning because it can be replaced by 1, 2, 3,.. [Hobson 1907, 23]. He suggests keeping in mind the concept of "adequate definition" of a number (in particular of irrational number): a number is adequately defined if we have the means of deciding, in respect to any arbitrarily assigned rational number, whether the number ordinally precedes or succeeds the assigned rational number. This is, according to Hobson, a necessary condition of the definition of a number, and it is clear that an adequate definition of an irrational number must supply us with directions for calculating, for any

\footnotetext{
12 The paper that resulted was received and read November $9^{\text {th }}, 1905$.
} 
prescribed integer $n$, by an arithmetic process, the first $n$ figures of the decimal representation of the irrational number.

Hobson defines $E$ to be the set formed by the rational numbers and by those irrational numbers that can be defined in a form involving only a finite number of words and signs, and including the use of the only "variable" $n(n=1,2,3 \ldots)$. Its members are adequately defined and the set is denumerable. Then, it is possible to prove that there exist irrational numbers adequately defined that do not belong to $E$. His proof runs as follows (when we confine ourselves to the interval $(0,1)$ of the continuum, which is in bijective correspondence with the continuum itself):

1) We can write the decimal representation of any denumerable set of adequate numbers (belonging to the interval $(0,1))$ in the matrix:

$$
\begin{aligned}
& x_{1}=p_{11}, p_{12}, p_{13 \ldots} \\
& x_{2}=p_{21}, p_{22}, p_{23 \ldots} \\
& x_{3}=p_{31}, p_{32}, p_{33 \ldots}
\end{aligned}
$$

In particular, all the numbers of $E$ can be represented there.

2) We observe that we can write the number $N$, represented by $\left(a_{1} a_{2} a_{3}, \ldots\right)$ where $a_{n}=p_{n n}+(-$ 1) ${ }^{p_{n n}}$, that is adequately defined and that differs from each row of the matrix.

Therefore, we conclude that $N$ cannot belong to $E$, otherwise it would and would not appear in the matrix at the same time. Hence, it cannot be formed involving the use of the "variable" $n$ alone $(n=1,2,3 \ldots)$ : it must be defined in a form involving the use of sets of parameters $a_{1}, a_{2}, \ldots$, these parameters being numbers already defined, arranged in the order type $\omega$ and different ${ }^{13}$ from the sequence $1,2,3 \ldots$

In this way, in the end he suggested that it is better to introduce inside the continuum a distinction between numbers formed with reference to $1,2,3 \ldots$ and numbers formed with reference to other sequences $a_{1}, a_{2}, \ldots$ than a distinction between finitely definable and not finitely definable numbers.

\footnotetext{
13 As an example, he gives the following definition of an irrational number $M$ : "Let the decimal representation of $M$ be such that the $n$-th figure is identical with the $n$-th figure in the decimal representation of $2^{1 / P n}$ where $P_{n}$ denotes the $n$-th of the prime numbers $2,3,5,7,11, \ldots$ Since $P_{n}$ is not expressible in finite terms as a function of $n$, the parameters of the definition may be taken to be the set of prime numbers". [Hobson 1907, 25]
} 
At the end of 1905, Russell [Russell 1906a] replied to Hobson's discussion of "contradictions", 14 by stressing that they all had the same form and that they were based on logical assumptions that needed to be modified. A few months later, by replying to Poincaré on the same topic, as we discuss below [Poincaré 1906], Russell [1906b] proposed the distinction between predicative and impredicative definitions and suggested three theories for establishing the formation of sets corresponding only to predicative definitions: the zig-zag theory, the no-classes theory, and the limitation of size-theory. In 1908, in the paper "Mathematical Logic as Based on the Theory of Types" [Russell 1908] he listed a whole series of antinomies as he thought that the mechanism at the basis of any antinomy was the same (self-reference) and could be solved through his ramified theory of types. (Only here did he mention König's paradox). It is interesting for our purposes, to recall that Russell introduced also Berry's paradox [Russell 1906b, 645 and Russell 1908, 153], that had been communicated to him by the author in a letter [see Garciadiego 1992, 136]. It ran as follows: "Some ordinals, e.g. $\omega, \omega^{2}, \omega^{\omega}$ are definable in a finite number of words. Let us suppose that there is any ordinal which is not so definable. The ordinals less than this particular one are a well-ordered series. Hence, if among them there are any which are not finitely definable, there is one of these less than all the others. The least number of the class is then the least ordinal which is not definable in a finite numbers of words. But this is absurd, for I have just defined it in thirteen words. Going back a little I infer that one not-finitely definable order cannot exceed another such; therefore there is at most one such; and this is again absurd" (Berry's letter in [Garciadiego 1992, 167-168]).

Russell described the paradox as follows [1908, 153]: “'The least integer not nameable in fewer than nineteen syllables' must denote a definite integer; in fact, it denotes 111,777 . But 'the least integer not nameable in fewer than nineteen syllables' is itself a name consisting of eighteen syllables; hence the least integer not nameable in fewer than nineteen syllables can be named in eighteen syllables, which is a contradiction”.

We have to keep these details in mind, because König was to consider them inside his 1914 monograph, when he would give his final treatment of antinomies.

\footnotetext{
14 The focus was on them, therefore they should be called "antinomies" here, but the original Russellian term was "contradiction".
} 


\section{Other relevant events of 1905 around antinomies}

Hobson's 1905 paper stimulated A. C. Dixon's reflections through its reference to the question of definability. So Dixon published his contradiction (not as an antinomy) inside the proof of the impossibility for a transfinite set to be well-ordered by a finite set of rules. Dixon [1907a] stated that an object was defined when the properties necessary to distinguish it from all other objects of mental activity were given. Since the number of elements available for use in any definition is finite (say $p$ ), the power of the set of objects described by such finite specifications could be neither greater nor less than $\aleph_{0}$. Still, the set of all real numbers has a cardinality greater than $\aleph_{0}$, so there had to be elements of the real number system which could not be given a finite definition. The same held for any other set whose cardinality is greater than $\aleph_{0}$ : it is impossible to give a finite description of each individual member. However, according to the (just published) well ordering theorem of Zermelo [1904], for any set which can be well-ordered by a finite system of rules $R$, each member of it can be specified in finite terms. For, if it is not true that every member can be so specified, there must be a first member which cannot, and it may be described in finite terms as "the first in the series which cannot be described in finite terms". And this is absurd. So, for any set whose cardinality is greater than $\aleph_{0}$, Dixon concluded that it could not be well-ordered by a finite set of rules. ${ }^{15}$ In other words, Dixon intended to prove this theorem through a reductio ad absurdum. The "absurdum" was the contradiction that would be later known as his “antinomy". 16

\footnotetext{
15 This did not contradict Zermelo's theorem because Zermelo [1904] had shown that it was possible to provide a wellordering of a transfinite set but without showing how to produce a specific ordering.

16 In the note at the end of his paper [1907a, 20], Dixon specified that "The idea on which this article is founded was mooted by me in a letter to Dr. Hobson in June of this year [1905: the paper was received on November 10 ${ }^{\text {th }}, 1905$ ], and in a very short note sent to the Society in July. A referee reported unfavourably on this note, but revised his opinion after reading Herr König's paper on the question in the last number of the Mathematische Annalen. I have expanded the note by his advice, and added some developments of the ideas". Hobson [1907, 21] confirmed that Dixon had obtained this result (on the basis of the notion of definability) before König published his own. The Hobson paper contains also a criticism of the proof (discussed in paragraph 9.). Dixon [1907b], received in March 1906, was a reply to Hobson's criticism, that concerned both König and himself. In particular in [1907, 317], he stressed that the number $N$ did not produce any contradiction. Such a construction "assumes the existence of a set of rules, say $R$, by which all adequate definitions of numbers are arranged in the type $\omega$. The rules $R$ are a part of the definition of $N$, and, if they cannot be stated in finite terms, then $N$ is not finitely specified; so that the contradiction is solved [...] suppose the first $n$ - 1 places to be already filled. Then the first $n-1$ decimal places in $N$ give no trouble, but when we come to the $n$-th decimal place, we are to fill it with a digit $a_{n}$ such that $a_{n}=a_{n}+(-1)^{a}{ }_{n}$. This is impossible, and hence the specification is to be rejected".
} 
In France, Jules Richard, a mathematics teacher at the Lycée of Dijon, inspired by J. Hadamard (see [Garciadiego 1992, 140-144]) communicated an antinomy ${ }^{17}$ to the Revue Générale des Sciences Pures et Appliquées ${ }^{18}$ : given that the set $T$ of real numbers that can be defined by finitely many French words is denumerable (let enumerate $u_{1}, u_{2} \ldots$ those numbers), we can form the real $N$ in this way: the integer part of $N$ is 0 , while its $n$-th decimal digit is $p+1$ if $u_{n}$ has the $n$-th decimal digit different from 8 or 9; else, the $n$-th- decimal digit of $N$ is 1 . By construction, $N$ will not occur in $u_{l}$, $u_{2} \ldots$ On the other hand, if we consider that $N$ is defined by means of a finite collection of letters, this must occur in $u_{1}, u_{2} \ldots$ He himself stressed that his paradox could take place because the definition of $N$ mentions $E$ to which $N$ must belong, but $E$ is yet to be defined, and the definition of $N$ makes sense only if the set $E$ is completely defined. Therefore, he concluded that the contradiction can disappear by recognizing that the definition of $N$ has no definite meaning.

\section{Second step: 1906.}

Poincaré's criticism of König's 1905 papers led the latter to deepen his reflections about settheory. As a first result he wrote a two-pages proof of the equivalence theorem [König 1906a], that was presented by Poincaré himself to the Académie des Sciences under the title "Sur la théorie des ensembles”. König's purpose was to accede to Poincaré's request to avoiding both induction and the concept of numbers, by promising to develop further constructive considerations in a future book. ${ }^{19}$

\footnotetext{
${ }^{17}$ He called it "contradiction".

18 See http://www.univ-nancy2.fr/poincare/chp/text/mittag-leffler224.xml, where a letter by Poincaré to Mittag-Leffler is transcribed: Poincaré wrote that "Il a paru il y a quelque temps dans la Revue Générale des Sciences une lettre de M. Richard à Hadamard sur la théorie des ensembles. On pourrait demander à M. Richard l'authorisation de reproduire sa lettere à la suite de l'article de König; cette letter contient en effect divers résultats paradoxaux obtenus par un raisonnement tout semblable à celui de König, et l'auteur en montre ensuite lui même le point faible" ("It has been published some time ago in the Revue Générale des Sciences a letter by Mr. Richard to Hadamard about set theory. One could ask Mr. Richard for the permission of printing his letter as an appendix to König's paper; this letter contains actually various paradoxical results obtained through a reasoning very similar to that by König, and the author himself points out its weak point".)
}

19 About this proof see Hinkis [2013 cap. 21] who offers an evaluation of König's contribution by considering both the successful "Gestalt" of his proof and its dubious accomplishment of the purpose that the author had in mind. Hinkis poses also the question [2013, 218-219] of the difficult classification of König's thought with respect to the foundational schools. In fact, König did not attached a label to himself, and the appearance of an eclectic attitude by him might be a good classification, in the sense that he picked up from each foundational viewpoint what he considered acceptable. In his 1914 book [1914, iii], he stressed that a "synthetic logic" was his aim, "having the same relationship with thought as mechanics has with planets' movements". It would satisfy "the strong requirements put by Poincaré for our mathematical and logical thought" and preserve "classical results of Cantor's set theory" (See Franchella [2000, 6064]). 
The second result, published under the title "Über die Grundlagen der Mengenlehre und das Kontinuumproblem (Zweite Mitteilung)" [König 1906b], concerns our topic: König presented his contradiction as a problem in itself, offered a solution to it, but then he proved that it lead to the unacceptable consequence that the second number class would be denumerable. Furthermore, he changed the way in which he formed the number that at the same time is and is not finitely definable.

Let us follow his argumentation.

He recalled that the set of all finitely definable numbers of the continuum is denumerable and specified that it can be written in a matrix according to Cantor:

$$
\begin{aligned}
& a_{11}, a_{12}, a_{13 \ldots} \\
& a_{21}, a_{22}, a_{23 \ldots} \\
& a_{31}, a_{32}, a_{33 \ldots}
\end{aligned}
$$

where each row should be interpreted as the list of the integers $a_{h k}, a_{h(k+1)}, \ldots$ present in the infinite continued fraction $\frac{1}{a_{h k}+\frac{1}{a_{h(k+1)}+\ldots}}$.

Yet, by Cantor's diagonal process, König formed a real number by adding an integer $d>0$ to each $a_{k k}$ and obtained:

$$
a_{k}=a_{k k}+d \text {. }
$$

The real number $\left(a_{1}, a_{2}, \ldots\right)$ was actually finitely defined but it did not belong to the matrix, i.e. to the set of all finitely definable real numbers, because, otherwise, for $k=n a_{k}=a_{k k}$ and $a_{k}=a_{k k}+d$ would hold at the same time. This reminds us immediately of Hobson's criticism of König's 1905 paper, that the author must have taken under serious consideration: he uses the same example that Hobson had given to criticizes his assumption (the notion of finitely definable numbers of the continuum) in order to construct a number of the continuum that is and is not finitely definable at the same time.

On this point, it can be useful to recall that the foundational viewpoints of the mathematicians at König's epoch were not clearly cut into three well-defined schools to which any mathematician should belong. The tripartition into schools is a historiographic tool, given a posteriori, to put some order into the intricate interplay of the various authors. So, there is no wonder that a scholar does not fit exactly into any of them. 
In order to solve this problem, König proposed a procedure that eventually lead to the proof that the second number class $\mathrm{Z}\left(\aleph_{0}\right)$ is denumerable: an unacceptable consequence.

The idea of the procedure was to transform $\left(a_{1}, a_{2}, \ldots\right)$ so that it would be not finitely defined also actually. In order to do so, König introduced the so-called "pseudofinite definitions", that are formed by a denumerable quantity of signs: after the $n$-th place of the number $\left(a_{1}, a_{2}, \ldots\right) \quad$ (König called this part of the definition, i.e. the first $n$ signs, the "Hauptteil" - and represented it by $H$ ), one writes the sign (N.V.) denumerably many times (N.V. means "Ne Varietur". The reason for this name will be clear in a few lines), obtaining

$$
b_{k}=H(N . V .)^{\omega}
$$

These definitions ${ }^{20}$ are equivalent respectively to the finite ones that begin with the same signs put before the (N.V.)'s and do not change anything (with respect to the corresponding finite definitions) in the content of the number that they contribute to build: there is only a change of form that transforms them into not-finitely definable numbers. Hence, König pretended to have solved the paradox by replacing the numbers that should not be finitely definable by these numbers that are not finitely definable (which are in a one-to-one correspondence with them).

König observed that the process of constructing and solving the paradox can be indefinitely repeated at successive levels. Namely, given the numbers $\left(b_{1}, b_{2}, \ldots\right)$, where each $b_{k}$ is of the form $H(N . V .)^{\omega}$, their set is denumerable, due to the above bijective correspondence between finite and pseudofinite definitions. Therefore, it can be represented in a matrix like that described at the beginning of this section:

$$
\begin{aligned}
& b_{11}, b_{12}, b_{13 \ldots} \\
& b_{21}, b_{22}, b_{23 \ldots} \ldots \\
& b_{31}, b_{32}, b_{33 \ldots}
\end{aligned}
$$

\footnotetext{
${ }^{20}$ It is clear that, by varying $d$, one obtains different sequences $\left(a_{1}, a_{2}, \ldots\right)$, as each $a_{k}$ has the form $a_{k}=a_{k k}+d$.
} 
According to König, by applying Cantor's diagonalization, one can generate a number $b_{k}=b_{k k}+d$ $(d>0)$ which gives origin to the paradox again as it is a finite form. In this case, in order to solve the paradox, it is necessary to add (N.V.) at least $\omega+1$ times after the $n$-the place of $\left(b_{1}, b_{2}, \ldots\right)$ :

$$
H(N . V .)^{\omega+1} \text {. }
$$

Namely, $H(N . V .)^{\omega}$ would still be one of the $b_{k}$ 's.

Also at this level it is possible to repeat the reasoning above: in general, when the paradox is solved for a subset of elements of the continuum by adding (N.V.) a certain denumerable number $x$ of times, then the paradox is formed again by collecting the new-definite elements into a denumerable matrix, applying to it Cantor's procedure of diagonalization and adding $d(d>0)$. The new paradox requires for its solution the addition of (N.V.) at least $x+1$ times.

After these remarks, König could give the proof that this solution lead to the (undesirable) conclusion that the second number class is denumerable. Firstly, he defined $\alpha$ as being a number "of the first kind" if $\alpha$ is the smallest number of the second number class such that $H(N . V .)^{\alpha}$ is the solution for the paradox formed at a certain step of his reasoning above. Correspondingly, he defined that a certain Hauptteil $H$ has the rank $\alpha$, if $\alpha$ is the first number of the second number class $^{21}$ such that $H$ becomes a consistent definition only if (N.V.) $)^{\alpha}$ is added to the sign $H$. Then he proved his result through the following two steps:

1) the set of the numbers of the second number class $Z\left(\aleph_{0}\right)$ that are of the first kind is denumerable;

2) every number of the second number class $Z\left(\aleph_{0}\right)$ is of the first kind.

The proof of 1) is immediate: the set is denumerable because different $H$ 's are linked to different $\alpha^{\prime}$ s $\left((\mathrm{N} . \mathrm{V} .)^{\omega}\right.$ is applied to the first $n$ places of numbers $\left(a_{1}, a_{2}, \ldots\right),(\mathrm{N} . \mathrm{V} .)^{\omega+1}$ is applied to the first $n$ places of numbers $\left(b_{1}, b_{2}, \ldots\right)$, and so on).

The proof of 2) is by reductio ad absurdum. Let $\alpha_{0}$ be the first number of the second number class that is not of the first kind. The $H$ 's that have their rank in the second number class are denumerable because their set is denumerable as the set of all finite sequences. Therefore, it is possible to represent them within a matrix like those above:

\footnotetext{
21 Poincaré [1909, 469] referred to this paper by König by considering Russell's theory of order types. By wondering whether it was possible to consider propositions of order $\alpha$ (for $\alpha$ a transfinite ordinal number), he stressed that König had produced a theory that did not differ essentially from Russell's: König had designated by A(NV) the objects of $1^{\text {st }}$ order; by $\mathrm{A}(\mathrm{NV})^{2}$ the objects of $2^{\text {nd }}$ order, and so on. He also remarked that König "n'hésite pas a introduire des $\mathrm{A}(\mathrm{NV})^{\alpha}$ où $\alpha$ est transfinie, sans d'ailleurs expliquer suffisamment ce qu'il entend par là" ("König does not hesitate to introduce the $\mathrm{A}(\mathrm{NV})^{\alpha} \mathrm{s}$ where $\alpha$ is transfinite, without explaining enough what he means by that").
} 


$$
\begin{aligned}
& q_{11}, q_{12}, q_{13 \ldots} \\
& q_{21}, q_{22}, q_{23 \ldots} \\
& q_{31}, q_{32}, q_{33 \ldots}
\end{aligned}
$$

where each $q_{i i}$ stands for an $H_{n}$, and then define by diagonalization a number $q^{\prime}{ }_{k}=q_{k k}+d(d>0)$, that König called $H_{0}$. It presents the paradox as before that can be solved by

$$
H_{0}(N . V .)^{\alpha_{0}}
$$

but not by

$$
H_{0}(N . V .)^{\alpha_{t}}
$$

if $\alpha_{i}<\alpha_{0}$.

Therefore, $\alpha_{0}$ would be of the first kind because it would be the first number of the second number class that solves the paradox for $H_{0}$. And this is a contradiction with respect to the definition of $\alpha_{0}$.

\section{Some criticisms}

Let us consider now the authors that criticized König's second paper. I mention in the first place Giulio Vivanti, because König himself would mention him in his book. Vivanti has been strongly interested in set theory and had presented [1889] Cantor's theorization of finite order-types in Italian. He pointed out [1907] some weak aspects of König's proofs. He began with König's 1905 proof of the fact that the continuum cannot be well-ordered and affirmed that its weak point was König's hypothesis that, if an element of the continuum is finitely defined, then the corresponding ordinal is also finitely defined. Namely, it is not enough that the ordinal be actually defined by a finite number of signs: it would also be necessary for the law of correspondence between the two series of numbers to be finitely definable, and this cannot be a priori admitted. Furthermore, the definition of a number $x$ as "the first number larger than every number finitely definable" presupposes infinitely many symbols, and, therefore, it is not a finite definition.

Vivanti believed that König had realized these difficulties and for this reason had written his 1906 paper (where he considered pseudofinite definitions). Vivanti analysed that paper also and noticed a weak step even in it: $b_{k}$ is not a finite sequence of signs but an infinite sequence of signs (because it contains $\left.H(N . V .)^{\omega}\right)$ therefore no paradox is generated. Consequently, also the undesired result of the denumerability of the second number class $Z\left(\aleph_{0}\right)$ disappears. 
Another criticism came from Gerhard Hessenberg who aimed specifically at König's notion of "finite representation" ("endliche Darstellung"). This was found in his volume "Grundbegriffen der Mengenlehre", which also appeared as a monograph in the series "Abhandlungen der Fries'schen Schule" [1906, 135-141 in the Abhandlungen; 612-621 in the monograph]. As a contribution to the Göttingen discussion around "paradoxes", ${ }^{22}$ he specified that, in case of paradoxes generated with reference to a "finite representation" there is a confusion between having "a" representation and having "one and the same" representation: "Es gibt für jede Zahl der zweiten Kasse eine endliche Darstellung, aber nicht eine endliche Darstellung aller Zahlen zweiter Klasse" ("There is for every number of the second class one finite representation, but not one finite representation for all the numbers of the second class" $\S 23$ ). Therefore, the statement "Since it is impossible to give one finite representation for all (alle) numbers of the continuum, there are numbers that are not finitely representable" is false. According to Zermelo's exposition [1908a, 192], Hessenberg meant that "finitely representable" was not an absolute notion, but a relative one, and was always related to a chosen language or notation. The conclusion that the set of all finitely representable objects must be denumerable holds only if one and the same system of signs are used for all of them, and the question whether a single individual can or cannot have a finite designation is in itself meaningless, since to any object we could, if necessary, arbitrarily assign any designation whatsoever. In addition, Hessenberg noted that all can as well be proved and refuted through the use of a contradiction, by recalling that, starting from the same notion as König [1905a and 1905b], F. Bernstein had sketched a proof that the continuum is equivalent to the second number class. ${ }^{23}$

It is also important to recall here A. Schoenflies, who in his paper "Über die logischen Paradoxien der Mengenlehre“ [Schoenflies 1906] referred to König's "solution” to set-theoretic paradoxes (i.e. introducing a difference between "classes" and "sets"). Schoenflies considered it as unsatisfactory and proposed to avoid references to self-containing sets, like the set of all sets, because a set represents a new concept that is appended to the single concepts that build the set, so self-reference should not be allowed [1906, p. 23].

\footnotetext{
22 On this subject see Peckhaus [1995] and [2004], [Peckhaus - Kahle 2002].

23 Zermelo [1908a, 192] stressed "To be sure, the promised realization of this 'proof' was never published".
} 
In 1906, Poincaré published the third part of his paper "La mathématique et la logique" , where he pointed out three antinomies - by Burali-Forti, ${ }^{24}$ by Zermelo-König and by Richard respectively - as the most famous.

He did not describe l'antinomie Zermelo-König, ${ }^{25}$ but he suggested as a general method for solving them that proposed by Richard himself: avoiding non-predicative definitions, i.e. definitions containing a vicious circle. ${ }^{26}$ The cause of the use of non-predicative notions in mathematics is the belief in the actual infinite (that allows the use of the word "every" (tous) inside a definition even if it refers to an infinite set, because such belief allows us to consider an infinite set as "known in its entirety”). So we should disbelieve it: "Il n'ya pas d'infini actuel; les Cantoriens l'ont oublié; et ils sont tombés dans la contradiction"("There is no actual infinity; the Cantorians forgot it and then fell into a contradiction") [1906, 316].

Peano, in his "Additione" to the 1906 paper "Super theorem de Cantor-Bernstein", presented a list of authors of antinomies, by specifying that in every time, "aliquo antinomia occurre in Mathematica, que, post aliquo discussione, accipe solutione. Solutione de antinomia es indicatione de puncto ubi es errore in ratiocinio"("Some antinomies occur in mathematics that find a solution after some discussion. A solution for an antinomy consists of pointing out where a mistake in the reasoning lies") [1906, 344]. His main attention is devoted to Richard's antinomy and Poincaré's solution to it. He stated that "solutione de antinomia dato ab Poincaré, que accusa definitiones de circulo vitioso, no es exacto [...] in omni definitione, secondo membro vel membro definiente, aequivalente ad primo, vel membro definito, contine semper notione de primo, et M. Poincaré contradice regula de usu commune, et redde impossibile omni definitione" ("Poincaré's solution to the antinomy, consisting of accusing its definition of referring to a vicious circle, is not right [...] in every definition the second number or the definiens, being equivalent to the first member, i.e. the definiendum, always contains it, and Mr. Poincaré contradicts this common rule and makes

\footnotetext{
${ }^{24}$ Henri Poincaré had referred in 1905 to Burali-Forti "antinomy" but aiming to show that Burali-Forti and Cantor had got opposite results (about trichotomy for transfinite cardinals). That showed, according to the author, that the pasigraphic approach by Burali-Forti was not exempt from mistakes. [Poincaré 1905, 825]

25 Curiously, the antinomy that Zermelo attributed to himself (see [Zermelo 1908a, 118-119] was Russell's antinomy. About this story see Rang - Thomas [1981] and Garciadiego [1985, 347].

26 As Cantini [2009, 890] stresses, Poincaré generalizes Richard's diagnosis of the antinomy, arguing that all the contradictions rely upon impredicative (circular) definitions and that the problem with impredicative classes is not that they are empty but that they have an undecided frontier [Poincare 1906, 310]. On this topic see also [Simmons 1994].
} 
impossible any definition") [1906, 353]. He then proposed his own opinion about the main weak point in Richard's example: "definitione de $N$ es dato parte in symbolos, et parte non in symbolos. Parte non symbolico contine idea de 'lingua commune', idea multo familiare ad nos sed non determinato, et causa de omni ambiguitate" (The definition of $N$ is given partly in symbols and partly not in symbols. The non-symbolic part contains ideas from ordinary language, an idea that is very familiar to us but not determinated, and that is the cause of all ambiguity") [1906, 357]. In other words, the very problem in Richard's construction is that part of it cannot be expressed in a clear-cut way according to the rules of mathematics. Within his strict symbolic world of the Formulario, such an antinomy cannot have a place. Therefore, he concluded ${ }^{27}[1906,358]$ with the famous dictum "exemplo de Richard non pertine ad Mathematica sed ad Linguistica" ("Richard's example does not concern mathematics but linguistics"). Peano mentioned, among others, also König [1906, 346] and stated: “Omni antinomia antiquo et recente, depende de consideratione de "infinito" ("Every antinomy, past and present, depends on considering the infinite"). The suggestion by some authors to avoiding infinity is cautious but it does not solve the problem as "infinito es in natura de plure quaestione" ("the infinite is in the nature of many questions") and, according to an old expression by the latin poet Oratius, naturam expelle furca, tamen usque recurret.

Finally, Zermelo’s 1908 paper “Neuer Beweis für die Möglichkeit einer Wohlordnung”, that principally aimed at a new proof of his well-ordering theorem, contained a reference to König's viewpoint about the theorem ${ }^{28}$ : he recalled the story of the "conditioned" proof that König had given at the Heidelberg Congress, stressed that König relied upon the axiom of choice and "thus accepting the most essential assumption of my theorem, he treated the question whether the continuum can be well-ordered as an unsolved problem in later publications, without regard for my already published note; but up to now he has abstained from giving public expression to his reservations about any specific step in my proof" [1908a, 192].

Furthermore, he specified how he solved all paradoxes concerning the set $W$ of all Cantor ordinals: “As already appears in a much simpler way from Russell's antinomy - it is not permissible to treat

27 Lolli [1985, 73-79] recalled the equivocations that such a statement had produced in the community of the mathematicians and explains its meaning very well.

28 Ebbinghaus-Peckhaus [2007, 68], referring to a Zermelo's letter to Hilbert, affirms that probably Zermelo herewith follows a request of Hilbert in spite of his opinion that König's arguments were nowhere to be taken seriously. 
the extension of every arbitrary notion as a set and that therefore the customary definition of set is too wide. But if in set theory we confine ourselves to a number of established principles such as those that constitute the basis of our proof - principles that enable us to form initial sets and to derive new sets from the given ones - then all such contradictions can be avoided" [1908a, 195]. The principles that he adduced in his paper were:

1) All elements of a set $M$ that have a property $P$ well-defined for every single element are the elements of another set $M_{P}$, a "subset" of $M ; 29$

2) All subsets of a set $M$ are the elements of a set $\mathcal{P}(M)$ determined by $M$.

3) A set $\mathrm{S}$ that can be decomposed into a set of disjoint parts $A, B, C \ldots$ each containing at least one element, possesses at least one subset $S_{1}$ having exactly one element in common with each of the parts $A, B, C \ldots$ considered.

That paper was followed [1908b] by the first axiomatization of set theory where he introduced the axiom of separation to avoid the formation of "the set of all sets" and "the sets of all ordinal numbers". He began with: 1) the domain of individuals ${ }^{30}$ which set theory is concerned with ("we shall call these individuals simply objects and among them are the sets"); 2) the fundamental relations between the objects of the domain - "to be an element of"; 3 ) the notion of subset (and of disjoint sets); 4) the notion of "being definite" - an assertion is said to be definite if the fundamental relations of the domain, by means of the axioms and the universally valid laws of logic, determine without arbitrariness whether it holds or not; a propositional function $G(x)$, in which the variable term $x$ ranges over all individuals of a class $K$, is said to be definite if it is definite for each single individual $x$ of the class $K$. Then, he gave the axioms: 1) the axiom of extensionality; 2) the axiom of elementary sets (the null set, the set $\{a\}$ and the set $\{a, b\}$ ); 3 ) the axiom of separation (whenever the propositional function $G(x)$ is definite for all elements of a set $M, M$ possesses a subset $M_{G}$ containing as elements precisely those elements $x$ of $M$ for which $G(x)$ is true); 4) the axiom of the power set; 5) the axiom of the union; 6) the axiom of choice; 7) the axiom of infinity. As for König's theorem, Zermelo considered it as irrelevant for the question of whether the continuum can be well-ordered; the well-ordering theorem had been stated and other paradoxes coming out of sets that are too large were avoided through a careful, axiomatized production of sets. In particular, he

\footnotetext{
${ }^{29}$ From 1) he derived the proposition stating the definition of the intersection of sets.

30 The domain itself is not a set in order to avoid the Russell antinomy [1908b, 203].
} 
stressed that the condition of 'being definite', which he required by a definition in order to make Richard's antinomy and the paradox of finite denotation (i.e. König's paradox) disappear. To be precise, the definition that the authors of these paradoxes gave cannot produce a set: "definable by means of a finite numbers of words" is not a definite definition, because the axiomatic system does not allow us to establish whether that condition holds or not [1908b, 202]. We recall here that in 1905 König had specified that his own notion of "definiteness" allowed a conceptual individuability, but stressed that it did not require an effective procedure that pointed out the individuals (see $\S 4$ of this paper). Zermelo, on his side, required an effective derivability on the basis of his axioms.

\section{Third step: König's paradox in his book.}

In $\S 7$ we have seen that in 1906 König had tried to prove the equivalence theorem by also responding to Poincaré's request to avoiding both induction and the concept of numbers. On that occasion he had promised to develop further constructive considerations in the future. The final treatment of his paradox originated out of König's development of Poincaré's idea of founding mathematics on intuition (Anschauung). He described this idea in his book Neue Grundlagen der Logik, Arithmetik und Mengenlehre ([König 1914] - see [Franchella 200] and [Guillaume 2008]) by stressing that his amounts to say that mathematics has its foundations in consciousness, constituted by various states (in German Denkbereiche), which are constituted in their turn by experiences (Erlebnisse). Their fundamental law is their non-contradictoriness, that is, the fact that the same Erlebnis cannot at the same time belong and not belong to the Denkbereich. Furthermore, it is impossible for everything to be determined in a Denkbereich, ${ }^{31}$ therefore there are sentences for which it is impossible to establish whether they are true or false. Nowadays we express this fact by stating that the law of the excluded middle is suspended. It is worthwhile to stress here that König did not use himself any label for it and that he suspended its validity without any emphasis: he considered obvious that it is impossible for everything to be determined in a Denkbereich, and from

\footnotetext{
${ }^{31} \mathrm{He}$ stressed that this was the main difference between his system and those presented by logical algebraists [1914, 152].
} 
this starting point he derived the impossibility of affirming the possibility of attaching either the value 'true' or the value 'false' to every statement.

Furthermore, he remarked that it is not possible to establish directly, for any Erlebnis, whether or not it belongs to a Denkbereich, because in most cases we have a partial grasp of it. That is why he introduced logical systems, i.e. axiomatic systems, for describing Denkbereiche. The axioms of logical systems must fulfill the fundamental law of Denkbereiche, i.e. they must be proved to be non-contradictory, and then the results of logical deductions from them supply us with some more details about our Denkbereiche. In particular, if we define $[x \sim \sim v]$ as "the proposition $x$ is true" and $\left[x \sim \sim v^{\prime}\right]$ as "the proposition $x$ is false", then we can accept in general $[x \sim \sim v] \leftrightarrow[x \sim \sim v$ '] in our system under the assumption that $[x \sim \sim v]$ and $\left[x \sim \sim v^{\prime}\right]$ are among the Erlebnisse for which it is impossible to establish whether or not they belong to the Denkbereich. In other terms, we can express this fact by saying that we can accept $[x \sim \sim v] \leftrightarrow\left[x \sim \sim v^{\prime}\right]$ under the assumption that $[x \sim \sim v]$ and $\left[x \sim \sim v^{\prime}\right]$ are among the formulas for which the law of bivalence does not hold.

This fact brought a solution for Russell's paradox. Namely, let us describe the set at issue by using his own notation [1914, 52-153]:

$$
\left[\left(x \operatorname{elem}_{\alpha} x\right) \sim \sim \mathrm{v}^{\prime}\right] \leftrightarrow\left[x \operatorname{elem}_{\alpha} R\right]
$$

This means that $x$ belongs to $R\left(\left[x\right.\right.$ elem $\left.\left._{\alpha} R\right]\right)$ if and only if it is false $\left(\sim \sim v^{\prime}\right)$ that $x$ belongs to $x$ ( $x$ $\left.\operatorname{elem}_{\alpha} x\right)$

Then, let us perform the substitution of $x$ by $R$, obtaining:

$$
\left[\left(R \text { elem }_{\alpha} R\right) \sim \sim v^{\prime}\right] \leftrightarrow[R \text { elem } \alpha \text { } R] .
$$

The last member of this biimplication is clearly equivalent to $\left(R\right.$ elem $\left._{\alpha} R\right) \sim \sim v$ (i.e., to the fact that $[\mathrm{R}$ elem $\alpha \mathrm{R}]$ is true), hence the whole biimplication can be written as follows:

$$
\left[\left(R \operatorname{elem}_{\alpha} R\right) \sim \sim v^{\prime}\right] \leftrightarrow\left[\left(R \text { elem }_{\alpha} R\right) \sim \sim v\right] .
$$

This is exactly an example of $[\mathrm{x} \sim \sim \mathrm{v}] \leftrightarrow\left[\mathrm{x} \sim \sim \mathrm{V}^{\prime}\right]$, where $\mathrm{x}$ is $\left(R\right.$ elem $\left._{\alpha} R\right)$ : we accept it under the assumption that both $\left[\left(R \operatorname{elem}_{\alpha} R\right) \sim \mathrm{v}^{\prime}\right]$ and $\left[\left(R\right.\right.$ elem $\left.\left._{\alpha} R\right) \sim \sim v\right]$ are not Erlebnisse of our Denkbereich, or, in other terms, that $\left(R\right.$ elem $\left._{\alpha} R\right)$ must be considered a formula that has no truthvalue in the system.

The same holds for the liar paradox $[1914,154]$. If we describe it as:

$$
[e \sim \sim v]=\left[e \sim \sim v^{\prime}\right]
$$


where " $e$ " means "Epimenides is telling a lie", we can keep this formula in our system, under the assumption that both $[e \sim \sim v]$ and $\left[e \sim \sim v^{\prime}\right]$ are not Erlebnisse of our Denkbereich, or, in other terms, that $e$ must be considered a formula that has no truth-value in the system.

König remarked [1914, 39] that there is no need to avoid self-reference in set theory (as, instead, Schoenflies had proposed), nor is any other intervention on sets necessary, except for checking the condition of their consistency. His own differentiation between "classes", "pure sets" and "usual sets" presented in the volume was not driven by the necessity of avoiding paradoxes but aimed to analyse the level of conceptualization involved in the definition of what is commonly called "set", starting from the fact that linking is the first act of thought. ${ }^{32}$ Namely, he defined classes as Denkbereiche where the same name was given to every Erlebnis and the Erlebnisse could not be different from each other; "pure sets" as Denkbereiche where the same name was given to every Erlebnis but the Erlebnisse could be different from each other and were supposed to be distinguishable from each other; "usual sets" as Denkbereiche where it was specified that the Erlebnisse were given and that the same name was attributed to them. In practice, classes consisted of simply naming things; pure sets consisted of collecting things sharing a property; usual sets required both the act of collecting and the existence of the Erlebnisse.

While the Russell paradox and the liar paradox found a solution, the Berry/Dixon and the Burali-Forti paradoxes were treated by showing that they did not exist actually as they were based on mistakes or misinterpretations. In any case, in König's volume, inspired by Poincaré's foundational perspective, set theory appeared free from antinomies. That is why König affirmed that his treatment would satisfy the strong requirements of Poincare for our mathematical and logical thought and preserve classical results of Cantor's set theory [1914, iii].

As for the Burali-Forti paradox, i.e. the paradox that the ordinal of the class of all the ordinals should at the same time be and not be the largest ordinal, König "dissolved" it by developing his reflection on the act of thought $[1914,256]$. We have already seen that the first act of thought is linking. The resulting "relation" can be either abstract or empirical. It is abstract when

\footnotetext{
32 See Franchella [2000].
} 
it is independent of the specification of the things which are linked; otherwise, it is empirical. According to this analysis, the order relation is "empirical". As an example he proposed to first consider a set $A=\{a, b, c\}$ on which is defined the relation $R=\{a<b, a<c, b<c\}$, and then another set $A^{\prime}=\{a, b, c, d\}$ on which is defined the relation $R^{\prime}=\{a<b, a<c, b<c, a<d, b<d, c<d\}$. By focusing for instance on $a$, we notice that relation $R^{\prime}$ contains one more property than $R$ (“ $\left.a<d "\right)$ and that this depends only on the fact that the set $A^{\prime}$ to which it refers contains one element more than $A(d)$, i.e. it depends on the things that it links. ${ }^{33}$ If the order relation is an empirical relation, König affirmed, then it is impossible to obtain the ordinal of the set of all the ordinals. Namely, the order relation to which that ordinal should refer $^{34}$ would be the same as for one of the elements of the set (the element that would be its ordinal), but this is impossible as the order relation is empirical and the two objects in correspondence to which it would be defined (i.e. the set of all the ordinals and the ordinal of it) are different. In this way, the whole paradox disappears since the set of all the ordinals does not have an ordinal. ${ }^{35}$

Finally, König reconsidered Berry/Dixon's paradox, expressed as “'the smallest integer whose name contains at least 100 words' is the name, containing less then 100 words, for an integer whose name should contain at least 100 words". According to König [1914, 214], "the smallest integer whose name contains at least 100 words" is not "a name for a number, but for the definition of a number. A number does not correspond to this name, but rather a rule for distinguishing this number from all other things". In other words, "the smallest integer whose name contains at least 100 words" is not a name for an integer whose name contains (and hence does not contain) at least 100 words, but it is a name for the definition of a number whose name contains at least 100 words. There is no paradox at all.

König was conscious that this paradox was essentially the same as his and therefore also his own was solved in this way once and for all. His 1906 treatment of the issue was based on a confusion between the writing of a definition of a number and the writing of the number. König

\footnotetext{
33 Another important empirical relation is that of "copula" ( $a$ is $b$ ), i.e. "equality". According to König [1914, 24], a "pure" copula, i.e. a copula independent of the things that it links, does not exist, because "equality" is always with respect to a certain aspect of things (this is the concept of "isology"), therefore it is not absolute (otherwise, it would be against the Grundnorm because it would be the same as affirming that two different things coincide).

${ }^{34} \mathrm{We}$ recall here that an ordinal is the order-type of a well-ordered set, i.e. it is obtained by abstracting (only) the nature - and not also the order - of its elements.

35 Although König affirms [1914, 255] that the set can be well-ordered, by explaining that the intuition grants that every set of ordinals is well-ordered.
} 
became conscious of the necessity of keeping the two things distinguished and used this distinction to let the paradox disappear.

That was the end of the tortuous life of König's paradox, which has a singular story with respect to the other paradoxes: it was considered a tool for proving the falsity of the continuum hypothesis; it was individuated as a problem in itself, and a very strange solution, with further peculiar consequences, was proposed; and finally it seemed to be not problematic at all.

Bibliography

Avigad, J., 2006. "Methodology and Metaphysics in the Development of Dedekind's Theory of Ideals" in : Ferreirós, J., Gray, J. (Eds.), The Architecture of Modern Mathematics. Oxford University Press, Oxford, 159-186.

Bernstein, F., 1901. Untersuchungen aus der Mengenlehre. Ph.D. Thesis Göttingen. Druck des Waisenshauses. Halle a.S.

Bernstein, F., 1905a. "Über die Reihe der transfiniten Ordnungszahlen". Mathematische Annalen 60, 187-193.

Bernstein, F., 1905b. “Zum Kontinuumproblem”. Mathematische Annalen 60, 463-464.

Burali-Forti, C., 1897. "Una questione sui numeri trasfiniti”. Rendiconti del circolo matematico di Palermo 11, 154-164; Engl. transl. in : van Heijenoort, J. (Ed.), From Frege to Gödel, Harvard U.P., Cambridge Mass., 1967, 104-111.

Cantini, A., 2009. "Paradoxes, Self-Reference and Truth in the $20^{\text {th }}$ Century", in : Gabbay, D.M., Woods, J. (Eds.), Handbook of the History of Logic vol. 5., Elsevier, Amsterdam, 875-1015.

Cantor, G., 1932. Gesammelte Abhandlungen mathematischen und philosophischen Inhalts. Zermelo, E. (Hsg.), Berlin, Springer.

Coffa, J. A., 1979. “The humble origins of Russell's paradox”. Russell 33, 31-37.

Copi, I., 1958. "The Burali-Forti paradox". Philosophy of science 25, 281-286.

Crossley, J.N., 1973. "A note on Cantor's theorem and Russell's paradox". Australasian Journal of Philosophy 51, 70-71.

Dauben, J.W., 1979. Georg Cantor: His Mathematics and the Philosophy of the Infinite. Princeton, Princeton U.P.

Dedekind, R., 1871. "Über die Komposition der binären quadratischen Formen”. Supplement X to the second edition of [Dirichlet, 1863]. Parts reprinted in [Dedekind, 1968], Volume 3, 223-261 and Dedekind [1964], 223-261; Engl. transl. with an introduction by J. Avigad, Carnegie Mellon Technical Report CMU-PHIL-162, 2004, also at https://www.andrew.cmu.edu/user/avigad/Papers/ ideals71.pdf.

Dedekind, R., 1877. Sur la théorie des nombres entiers algébriques. Paris, Gauthier-Villars.

Dedekind, R., 1895. "Über die Begründung der Idealtheorie". Nachrichten von der Königlichen Gesellschaft der Wissenschaften zu Göttingen, Mathem.-phys. Klasse, 1895, 106-113. Reprinted in [Dedekind 1968], Volume 2, 50-58. 
Dedekind, R., 1968. Gesammelte mathematische Werke. (Fricke, R., Noether, E., Ore, O. eds.). New York, Chelsea Publishing Co. Online at http://gdz.sub.uni-goettingen.de/en/.

Dirichlet, P.G.L., 1863. Vorlesungen über Zahlentheorie. Braunschweig, Vieweg. Subsequent editions in 1871, 1879, 1894, with supplements by Richard Dedekind.

Dixon, A.C., 1907a. "On well-ordered aggregates". Proceedings of the London Mathematical Society 4, 18-20.

Dixon, A.C., 1907b. "A question in the theory of aggregates". Proceedings of the London Mathematical Society 4, 317-319.

Ebbinghaus, H-D., 2007. "Zermelo and the Heidelberg Congress 1904”. Historia Mathematica 34, 428-432.

Ebbinghaus, H-D., Peckhaus, V., 2007. Ernst Zermelo : An Approach to His Life and Work. Berlin, Springer.

Edwards, H.M., 1980. "The Genesis of Ideal Theory". Archiv for History of Exact Sciences 23, 321-378.

Edwards, H.M., 1983. "Dedekind's Invention of Ideals”. Bull. Lond. Math. Soc. 15, 8-17.

Edwards, H.M., 1992. "Mathematical Ideals, Ideals, and Ideology", The Mathematical Intelligencer 14(2), 6-19.

Ferreirós, J., 1999. Labyrinths of Thought. A History of Set Theory and its Role in Modern Mathematics. Birkhäuser, Basel.

Franchella, M., 1998. Some contributions to the history of logic in the $20^{\text {th }}$ century. Cuem, Milano. Franchella, M., 2000. "Towards a Re-evaluation of Julius König's Contribution to Logic", The Bulletin of Symbolic Logic, 6(1), 45-66.

Frei, G., (ed.) 1985. Der Briefwechsel David Hilbert - Felix Klein (1886-1918). Vandenhoek \& Ruprecht. Göttingen.

Garciadiego, A., 1985. "The emergence of the non-logical paradoxes of the theory of sets. 19031908". Historia Mathematica 12, 337-351.

Garciadiego, A., 1986. "On rewriting the history of the foundations of mathematics at the turn of the century". Historia Mathematica 13, 39-41.

Garciadiego, A., 1992. Bertrand Russell and the Origins of Set-theoretic Paradoxes. Birkhäuser, Basel.

Grattan-Guinness, I., 1976. "On the mathematical and philosophical background to Russell's The Principles of Mathematics", in : Thomas, J.E., Blackwell, K.(eds.), Russell in review. Hakkert \& Co., Toronto, 157-173.

Grattan-Guinness, I., 1978. "How Bertrand Russell discovered his paradox", Historia Mathematica 5, 127-137.

Grattan-Guinness, I., 1981. "Are there paradoxes of the set of all sets?". International Journal of mathematical Education, Science \& Technology 12, 9-18.

Grattan-Guinness, I., 2000. The Search For Mathematical Roots, 1870-1940. Princeton U.P., Princeton.

Guillaume, M., 2008. "Some of Julius König's mathematical dreams in his New Foundations of Logic, Arithmetic, and Set Theory", in : van Atten, M., Boldini, P., Bourdeau, M., Heinzmann, G. (eds.) One hundred years of Intuitionism (1907-2007). Birkhäuser, Basel, 178-197.

Guillemot, M., 1981 "La communication de Gyula König au Congrès de 1904”. Séminaire d'histoire des mathématiques de Toulouse, 3, 57-82.

Hannequin, A., 1895. Essai critique sur l'hypothèse des atomes dans la science contemporaine. Paris, Masson.

Hausdorff, F., 1904. "Der Potenzbegriff der Mengenlehre". Jahresbericht der Deutschen Mathematiker-Vereinigung 13, 569-571.

Hausdorff, F., 2012, Gesammelte WerkeBd. IX: Korrespondenz. Springer, Heidelberg.

van Heijenoort, J., 1967. From Frege to Gödel. A Source Book in Mathematical Logic, 1879-1931, Harvard University Press, Cambridge, Mass. 
Hessenberg, G., 1906. Grundbegriffe der Mengenlehre. Vandenhoeck und Ruprecht, Göttingen (see also Abhandlungen der Fries'schen Schule, Neue Folge, Bd. 1, 478 -706).

Hilbert, D., 1897. "Zahlbericht”, Jahresber. DMV 4, 175-546.

Hilbert, D., 1900. "Mathematische Probleme", Nachrichten von der Königlichen Gesellschaft der Wissenschaften zu Göttingen, 253-297; Engl. transl. of excerpts in : Ewald, W.B. (ed.), From Kant to Hilbert: A Source Book in the Foundations of Mathematics. Vol. II. Clarendon Press, Oxford, 1996, 1096-1105.

Hilbert, D., 1926. "Über das Unendliche”, Mathematische Annalen 95, 161-190; Engl. transl. in : van

Hinkis, A., 2013. Proofs of the Cantor-Bernstein Theorem. A Mathematical Excursion. Springer, Berlin.

Hobson, E.W., 1905. "On the General Theory of Transfinite Numbers and Order Types". Proceedings of the London Mathematical Society 3, 170-188.

Hobson, E.W., 1907. "On the arithmetical continuum". Proceedings of the London Mathematical Society 4, 21-27.

Kleiner, I., 2007. A History of Abstract Algebra. Birkhäuser, Boston.

König, J., 1905a. "Zum Kontinuum-Problem" in : Krazer, A. (Ed.), Verhandlungen des Dritten Internationalen Mathematiker-Kongresses in Heidelberg vom 8 bis 13 August 1904. Teubner, Leipzig, 1905, 144-147; also in Mathematische Annalen 60, 177-180.

König, J., 1905b. "Über die Grundlagen der Mengenlehre und das Kontinuumproblem", Mathematische Annalen 61, 156-160; Engl. transl. in : van Heijenoort, J. (Ed.), From Frege to Gödel, Harvard U.P., Cambridge Mass., 1967, 145-149. Citations from this paper come from the English translation.

König, J., 1906a. "Sur la théorie des ensembles". Comptes rendus hebdomadaire des séances de l'Academie des Sciences, Paris 143, 110-112.

König, J., 1906b. "Über die Grundlagen der Mengenlehre und das Kontinuumproblem. Zweite Mitteilung”. Mathematische Annalen 63, 217-221.

König, J., 1914. Neue Grundlagen der Logik, Arithmetik und Mengenlehre. Von Veit, Leipzig.

Kowalewski, G. 1950. Bestand und Wandel. Oldenbourg. München.

Krazer, A. 1905. (Hrsg.) Verhandlungen des dritten internationalen Mathematiker-Kongresses in Heidelberg vom 8.-13. August 1904. Teubner, Leipzig.

Kummer, E., 1847a. "Zur Theorie der complexen Zahlen”, J. Reine Angew. Math. 35, 319-326.

Kummer, E., 1847b. "Über die Zerlegung der aus Wurzeln der Einheit gebildeten complexen Zahlen in ihre Primfactoren”. J. Reine Angew. Math. 35, 327-367.

Kummer, E., 1851. "Mémoire sur la théorie des nombres complexes composés de racines de l'unité et de nombres entiers". J. Math. Pures Appl. 16, 377-498.

Lindenbaum, A., Tarski, A., 1926. "Communication sur les recherches de la théorie des ensembles.“, Comptes Rendus des Séances de la Societé des Sciences et des Lettres de Varsovie, Classe III, 19, 299-330.

Lolli, G., 1985. "Quasi alphabetum: Logica ed enciclopedia in G. Peano" in : Lolli, G., Le ragioni fisiche e le dimostrazioni matematiche. Il Mulino, Bologna, 49-84.

Lolli, G., 2001. "Definability as a mathematical concept before and after Gödel” in : Bottazzini, U., Dahan, A. (Eds.), Changing Images of Mathematics, Routledge, London, 207-221.

Lolli, G., 2013. Nascita di un'idea matematica. Edizioni della Normale, Pisa.

Majer, U., 1993a. "Hilberts Methode der idealen Elementen und Kants regulativer Gebrauch der Ideen”. Kant Studien 84, 51-77.

Majer, U., 1993b. "Das Unendliche - Eine blosse Idee? ”, Revue Internationale de Philosophie 47, 319-341.

Meschkowski, H. 1967. Probleme des Unendlichen. Werk und Leben Georg Cantors. Vieweg, Braunschweig. 
Moore, G. H., Garciadiego, A., 1981. "Burali-Forti's Paradox: A Reappraisal of Its Origins", Historia Mathematica 8, 319-350.

Moore, G.H., 1982. "Zermelo's Axiom of Choice: its Origins, Development and Influence". Springer, New York.

Moore, G.H., 1988. “The Roots of Russell's Paradox”. Russell N. S. 8, 46-56.

Moore, G.H., 1989. "Towards a History of Cantor's Continuum Problem" in : Rowe, D., McClearly, J. (Eds.), The History of Modern Mathematics. Academic Press, New York, 79-121.

Moore, G.H., 1995. 'The Origins of Russell's Paradox: Russell, Couturat, and the Antinomy of Infinite Number'. In Hintikka, J., (ed.) Essays on the Development of the Foundations of Mathematics. Kluwer, Dordrecht, 215-239.

Murawski, R., 2002. 'Leibniz's and Kant's Philosophical Ideas and the Development of Hilbert's Programme", Logique et Analyse 45, 421-437.

Von Neumann, J.,1923. "Zur Einführung der transfiniten Zahlen”, Acta litterarum ac scientiarum Regiae Universitatis Hungaricae Francisco-Josephinae, Sectio scientiarum matematicarum 1, 199208; Engl. transl. : van Heijenoort, J. (Ed.), From Frege to Gödel, Harvard U.P., Cambridge Mass., 1967, 346-354. Citations from this paper come from the English translation.

Oberschelp, A., 1994. Allgemeine Mengenlehre. BI, Mannheim-Leipzig-Wien.

Peano, G., 1906. "Super theorema de Cantor-Bernstein et additione", Rendiconti del Circolo matematico di Palermo 1906, 21, 360-366; then in Peano, G., 1957. Opere scelte, vol. I. Cremonese, Roma, 337-358. Citations of this paper come from the 1957 edition.

Peckhaus, V., 1990. Hilbertprogramm und Kritische Philosophie. Das Göttinger Modell interdisziplinärer Zusammenarbeit zwischen Mathematik und Philosophie, Vandenhoeck \& Ruprecht, Göttingen.

Peckhaus, V.,1995. “The Genesis of Grelling's Paradox”, in : Ingolf, M., Stelzner, W. (Hsg.), Logik und Mathematik. Frege-Kolloquium Jena 1993. Walter de Gruyter, Berlin, 269-280.

Peckhaus, V., 2004. "Paradoxes in Göttingen", in : Link, G. (Ed.), One Hundred Years of Russell's Paradox. De Gruyter, Berlin, 501-515.

Peckhaus, V. , Kahle, R., 2002. "Hilbert's Paradox". Historia Mathematica 29, 157-175.

Poincaré, H., 1905. "Les mathématiques et la logique (Part 1 of 3)". Revue de Métaphysique et de Morale 13, 815-835.

Poincaré, H., 1906. "Les mathématiques et la logique (Part 3 of 3)". Revue de Métaphysique et de Morale 14, 294-317.

Poincaré, H., 1909. "La logique de l'infini”. Revue de Métaphysique et de Morale 17, 461-482.

Purkert, W., 2002. "Grundzüge der Mengenlehre - Historische Einführung” in : Brieskorn, E. et al. (Eds.), Hausdorff, F., Gesammelte Werke, vol. II: Grundzüge der Mengenlehre. Springer-Verlag Berlin, 1-89.

Purkert, W., 2015. “On Cantor's Continuum Problem and Well Ordering: What Really Happened At The 1904 International Congress Of Mathematicians In Heidelberg”, in : Rowe, D.E., Horng, W.-S. (Eds.) A Delicate Balance: Global Perspectives On Innovation And Tradition In The History Of Mathematics, Birkhäuser, Heidelberg, 3-24.

Purkert, W., Ilgauds, H.J.,1987. Georg Cantor 1845-1918. Birkhäuser, Basel.

Rang, B., Thomas, W., 1981. “Zermelo's discovery of the Russell paradox”. Historia Mathematica 8, 15-22.

Russell, B., 1896. "Review of Hannequin 1895”. Mind 5, 410-417.

Russell, B., 1902. "Letter to Frege, June 16, 1902" in : van Heijenoort, J. (Ed.), From Frege to Gödel, Harvard U.P., Cambridge Mass., 1967, 124-125.

Russell, B., 1903. The Principles of Mathematics. Cambridge U.P., Cambridge.

Russell, B., 1905. "Sur la relation des mathématiques à la logistique". Revue de Métaphysique et de Morale 13, 906-917.

Russell, B., 1906a. "On some difficulties in the theory of transfinite numbers and order types". Proceedings of the London Mathematical Society 4, 29-53. 
Russell, B., 1906b. "Les paradoxes de la logique". Revue de Métaphysique et de Morale 14, 627650.

Russell, B., 1908. "Mathematical Logic as Based on the Theory of Types". American Journal of Mathematics, 30: 222-262; repr. in van Heijenoort, J., (ed.), From Frege to Gödel. Harvard University Press, Cambridge, Mass., 1967, 152-182.

Schoenflies, A., 1906. "Über die logischen Paradoxien der Mengenlehre". Jahresbericht der Deutschen Mathematiker-Vereinigung 15, 19-25.

Schoenflies, A., 1922. "Zur Erinnerung an Georg Cantor". Jahresbericht der Deutschen Mathematiker-Vereinigung 31, 97-106.

Shegalkin, I. , 1907. Transinitnyje Tschisla (Transfinite Numbers). University Press, Mosca.

Simmons, K., 1994. “A Paradox of Definability: Richard's and Poincaré's Way Out”. History and Philosophy of Logic 15, 33-44.

Stillwell, J., 2002. Mathematics and Its History. Springer, New York, $2^{\text {nd }}$ ed.

Stillwell, J., 2014. "Ideal Elements in Hilbert's Geometry", Perspective On Science 22(1), 35-55.

Szamuely, T., 2006. "Contribution to algebraic number theory" at http://www.renyi.hu/ szamuely/ pano.pdf

Szénássy, B., 1992. History of Mathematics in Hungary Until the $20^{\text {th }}$ Century. Springer, New York.

Tapp, C., 2013. An der Grenzen des Endlichen: das Hilbertsprogramm im Kontext von Formalismus und Finitismus. Springer Spektrum, Berlin-Heidelberg.

Vivanti, G., 1889. "Fondamenti della teoria dei tipi ordinati". Annali di Matematica Pura ed Applicata 1, 1-35.

Vivanti, G., 1907. "Sopra alcune recenti obiezioni alla teoria dei numeri transfiniti". Rendiconti del Circolo Matematico di Palermo 25, 205-208.

Zermelo, E., 1904. "Beweis, dass jede Menge wohlgeordnet werden kann". Mathematische Annalen 59, 514-516.

Zermelo, E., 1908a. "Neuer Beweis für die Möglichkeit einer Wohlordnung", Mathematische Annalen 65, 107-128; in : van Heijenoort, J. (Ed.), From Frege to Gödel, Harvard U.P., Cambridge Mass., 1967, 183-198. Citations from this paper come from the English translation.

Zermelo, E., 1908b. "Untersuchungen über die Grundlagen der Mengenlehre. I", Mathematische Annalen 65, 261-281; Engl. transl. in : van Heijenoort, J. (Ed.), From Frege to Gödel, Harvard U.P., Cambridge Mass., 1967, 199-215. Citations from this paper come from the English translation. 